\title{
ORIGINAL RESEARCH \\ Stenting versus Medical Treatment for Severe Symptomatic Intracranial Stenosis
}

\author{
C.-W. Tang \\ F.-C. Chang \\ C.-M.Chern

\begin{abstract}
BACKGROUND AND PURPOSE: Intracranial atherosclerosis is especially prevalent in Asians, but intracranial stent placement and medical treatment for severe intracranial stenosis are controversial. Thus, we compared long-term outcomes of these 2 therapeutic approaches in an Asian population.
\end{abstract}

Y.-C. Lee

H.-H. Hu

I.-H. Lee

\begin{abstract}
MATERIALS AND METHODS: Patients with angiographically proved severe ( $\geq 70 \%$ ) symptomatic intracranial atherosclerosis, with or without stent placement, were retrospectively reviewed at a single center between 2002 and 2009, with adjustments for age, sex, vascular risk factors, degree of baseline stenosis, and baseline functional status.
\end{abstract}

RESULTS: Of the 114 patients followed from 3 to 36 months (mean, 17.3 months) after initial diagnosis, 53 received 56 stents in addition to medical treatment (stent-placement group), and 61 matched patients received only medical treatment (medical group). Total clinical events, including stroke, TIA, and vascular death, were $12(22.6 \%)$ and $15(24.6 \%)$ in the stent-placement and medical groups, respectively $(P=.99)$. The stent-placement group had significantly better functional outcomes than the medical group $(94.3 \%$ versus $78.7 \%$ for $\mathrm{mRS}$ scores of $0-3, P=.045)$. Most events in the stent-placement group occurred within the first week of the periprocedural period $(17.0 \%)$ as minor embolic or perforator infarctions, and the rate of events decreased thereafter $(5.7 \%, P=.07)$. Stent placement over the perforator-rich MCA and BA independently predicted periprocedural events on multivariate regression analysis. In the medical group, events increased in frequency $(21.7 \%)$ and severity with time.

CONCLUSIONS: Although the total ischemic event rate was similar in the 2 groups during a 3-year follow-up, the stent-placement group had a more favorable functional outcome despite minor periprocedural strokes.

\begin{abstract}
ABBREVIATIONS: $\mathrm{ACA}=$ anterior cerebral artery; $\mathrm{ADC}=$ apparent diffusion coefficient; $\mathrm{B}=$ balloon-mounted stent; $\mathrm{BA}=$ basilar artery; $\mathrm{BP}=$ blood pressure; $\mathrm{CS}=$ carotid siphon; $\mathrm{CVA}=$ cerebrovascular accident; DSA = digital subtraction angiography; DWI = diffusion-weighted imaging; $\mathrm{HbA} 1 \mathrm{C}=$ glycated hemoglobin; $I \mathrm{CA}=$ internal carotid artery; $\mathrm{ICH}=$ intracerebral hemorrhage; $\mathrm{MCA}=$ middle cerebral artery; $\mathrm{mRS}=$ modified Rankin Scale; $\mathrm{NIH}=$ National Institutes of Health; $\mathrm{NS}=$ not significant; $\mathrm{SAH}=$ subarachnoid hemorrhage; TIA = transient ischemic attack; $\mathrm{VA}=$ vertebral artery; VBJ = vertebrobasilar junction; WASID $=$ Warfarin-Aspirin Symptomatic Intracranial Disease
\end{abstract}

ntracranial arterial stenosis accounts for 33\%-54\% of ischemic strokes in Asian populations. ${ }^{1}$ The risk of ischemic stroke from a symptomatic stenotic intracranial artery is high despite medical treatment. ${ }^{2}$ According to the prospective WASID study, the 1-year risk of ischemic stroke in the territory of a symptomatic stenotic $(\geq 50 \%)$ intracranial artery was

\section{Received July 19, 2010; accepted after revision September 21}

From the Department of Neurology (C.-W.T.), Suao Veterans Hospital, Yilan County, Taiwan; Departments of Radiology (F.-C.C.) and Neurology (C.-M.C., Y.-C.L., H.-H.H., I.-H.L.), Taipei Veterans General Hospital, Taipei, Taiwan; Department of Radiology (F.-C.C.), National Yang-Ming University School of Medicine, Taipei, Taiwan; and Department of Neurology (C.-M.C., Y.-C.L.) and Institute of Brain Science (H.-H.H., I.-H.L.), National Yang-Ming University, Taipei, Taiwan.

This work was supported by Veterans General Hospitals University System of Taiwan Joint Research Program (VGHUST99-P1-07), National Science Council (NSC-97-2314-B-480002-MY3, 97-3111-B-010-004), and Taipei Veterans General Hospital (V98B2-008, V98E1-009, V99C1-069, V99E1-010) in Taiwan

Please address correspondence to I-Hui Lee, MD, No. 201, Sec. 2, Shih-Pai Rd, Taipei 112 , Taiwan; e-mail: ihlee@vghtpe.gov.tw

Indicates open access to non-subscribers at www.ajnr.org

Indicates article with supplemental online table

Indicates article with supplemental online figure.

DOI 10.3174/ajnr.A2409 approximately $11 \%-12 \%$, despite high-dose aspirin or warfarin therapy. With a degree of stenosis $>70 \%$, the ipsilateral stroke rate at 1 year increased to $18 \%-23 \% .^{3,4}$

With the emergence of intracranial angioplasty and stent placement, the disease course and therapeutic trends have changed. ${ }^{5,6}$ In a review of 1177 procedures of intracranial stent placement from 31 studies, the technical success rate was $>90 \%$; however, widely variable periprocedural complications $(4.4 \%$ $50 \%$ ) were observed. ${ }^{7,8}$ A higher degree of stenosis ( $\geq 70 \%$ ) was not correlated with more of these complications. ${ }^{4,9-11}$ Using the NIH Wingspan Multicenter Stent-Placement Registry, a comparison between 158 patients receiving stents and 254 matched patients from the WASID study suggested possible benefits of stent placement over medical treatment for severe (70\%-99\%) intracranial stenosis (stroke and death rate: $13 \%$ versus $16 \%$ at 6 months). ${ }^{12}$ However, a recent historical cohort study on severe $(>50 \%)$ intracranial stenoses showed a similar combined ischemic event rate for the occurrence of TIA, stroke, and vascular death between patients receiving medical treatment and those receiving endovascular stent placement (24\% versus $28.3 \%) .^{13}$ More studies comparing long-term outcomes between medical treatment and endovascular stent placement for intracranial stenosis are, therefore, warranted, particularly in Asian populations. 


\begin{tabular}{|c|c|c|c|}
\hline & $\begin{array}{l}\text { Medical } \\
\text { Group } \\
(n=61)\end{array}$ & $\begin{array}{l}\text { Stenting } \\
\text { Group } \\
(n=53)\end{array}$ & $\begin{array}{c}P \\
\text { Value }\end{array}$ \\
\hline Age (yr) (mean \pm SD) & $66.9 \pm 12.3$ & $66.1 \pm 11.9$ & NS \\
\hline Male (No.) (\%) & $51(83.6 \%)$ & $44(83.0 \%)$ & NS \\
\hline \multicolumn{4}{|l|}{ Vascular risk factors, history of } \\
\hline Diabetes (№.) (\%) & $28(45.9 \%)$ & $25(47.2 \%)$ & NS \\
\hline Lipid disorder (No.) (\%) & $22(36.1 \%)$ & $17(32.1 \%)$ & NS \\
\hline Cigarette smoking (№.) (\%) & $20(32.8 \%)$ & $17(32.1 \%)$ & NS \\
\hline Stroke/TIA (No.) (\%) & $18(29.5 \%)$ & $17(32.1 \%)$ & NS \\
\hline $\begin{array}{l}\text { Ischemic heart disease } \\
\text { (№.) (\%) }\end{array}$ & $21(34.4 \%)$ & $16(30.2 \%)$ & NS \\
\hline $\begin{array}{l}\text { Peripheral vascular disease } \\
\text { (№.) (\%) }\end{array}$ & $4(6.6 \%)$ & $4(7.5 \%)$ & NS \\
\hline \multicolumn{4}{|l|}{ Presenting symptoms } \\
\hline Ischemic stroke (No.) (\%) & $23(38.3 \%)$ & $19(35.8 \%)$ & NS \\
\hline TIA (No.) (\%) & $38(62.3 \%)$ & $34(64.2 \%)$ & NS \\
\hline \multicolumn{4}{|l|}{ Functional status at presentation } \\
\hline \multicolumn{4}{|l|}{ Location of stenosis } \\
\hline Anterior circulation (No.) (\%) & $45(60.0 \%)$ & $32(57.1 \%)$ & NS \\
\hline Posterior circulation (No.) (\%) & $30(40.0 \%)$ & $24(42.9 \%)$ & NS \\
\hline \multicolumn{4}{|l|}{ Pattern of stenotic vessel } \\
\hline Isolated intracranial stenosis & $28(45.9 \%)$ & $33(58.9 \%)$ & NS \\
\hline Concomitant extracranial stenosis & $33(54.1 \%)$ & $20(35.7 \%)$ & NS \\
\hline $\begin{array}{l}\text { Percentage of stenosis at presentation } \\
\text { Follow-up time }\end{array}$ & $80.5 \%$ & $79.7 \%$ & NS \\
\hline $\begin{array}{l}\text { Observation period in } \\
\text { months (mean } \pm S D \text { ) }\end{array}$ & $17.0 \pm 11.0$ & $17.2 \pm 10.5$ & NS \\
\hline
\end{tabular}

We conducted a longitudinal observation of 114 Taiwanese patients with angiographically proved severe $(70 \%-99 \%)$ symptomatic intracranial stenosis, including 53 patients receiving endovascular stent placement and 61 matched patients receiving medical treatment, with immediate and long-term outcomes compared during a 3-year follow-up period.

\section{Materials and Methods}

\section{Subject Enrollment}

Patients with DSA-proved severe (70\%-99\%) symptomatic intracranial arterial stenosis at Taipei Veterans General Hospital between October 2002 and October 2009 were reviewed retrospectively. Specific causes other than atherosclerosis, such as Moyamoya syndrome, vasospasm, vasculitis, and compression stenosis secondary to tumor or infarction/hemorrhage, were excluded. The medical group received only medical treatment, and the stent-placement group received additional endovascular stent placement. The stent-placement group included all patients who had received intracranial stent placement between October 2002 and October 2009 at the center. Patients who underwent only endovascular angioplasties were excluded from this study. For a matched comparison, disabled patients with mRS scores of $>3$ in the medical group were excluded because the inclusion criterion for the stent-placement group was an mRS score of 1-3. The vascular risk factors/concomitant medical diseases, anatomic locations of stenosis, stenotic degree, and baseline mean mRS scores were all matched between the 2 groups to avoid selection bias (Table 1). The observation time was 3-36 months from the endovascular procedure in the stent-placement group ( $17 \pm 11.0$ months) or from the initial diagnosis in the medical group (17.2 \pm 10.5 months). Patients with incomplete clinical data or unmatched demographic character-
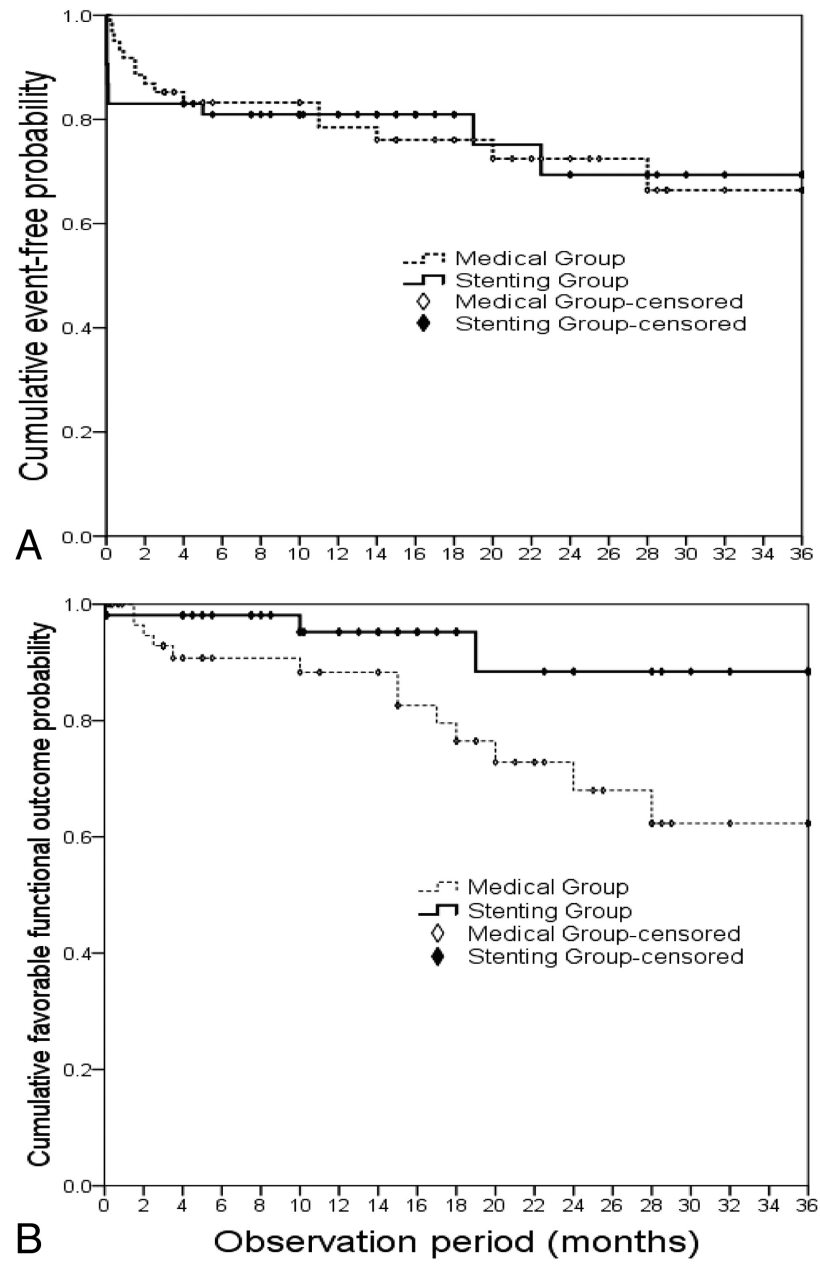

Fig 1. A, Kaplan-Meier curve of cumulative event-free probability. Note the stentplacement group drops $17 \%$ within the first week due to periprocedural complications and then slides modestly thereafter. In contrast, the medical group declines progressively with time. After 3 years, the event-free probabilities of the 2 groups fall similarly. $B$, KaplanMeier curve of cumulative favorable probability defined as mRS scores of $0-3$. Note that the stent-placement group has a markedly better long-term functional outcome $(P=.045)$.

istics were excluded, as listed in the enrollment flow chart (On-line Fig 1).

\section{Therapeutic Modalities}

Endovascular angioplasty and stent placement were performed for patients with severe (70\%-99\%) symptomatic intracranial atherosclerosis despite antithrombotic and/or anticoagulant treatment. All patients in both stent-placement and medical groups were required to have preserved functional activities (mRS score, $1-3$ ) and no contraindications for endovascular procedures (eg, contrast allergy, renal failure, coagulopathy, advanced malignancy). The decision was thoroughly discussed in a weekly conjoint conference of neurologists, neuroradiologists, and neurosurgeons. Following endovascular angioplasty and stent placement performed by qualified interventional neuroradiologists, patients were transferred to a stroke intensive care unit for strict blood pressure control to prevent hyperperfusion. Brain MR imaging, including DWI and ADC mapping, was performed on the day following intervention to exclude any asymptomatic complications. Double antiplatelet (aspirin and clopidogrel) therapy was given as standard treatment, if tolerated, from 1-3 days before to at least 3 months after the procedure. ${ }^{14}$ In-stent restenosis (>50\%) was monitored by DSA or CT angiography at an interval of 3-6 months 
Baseline mRS

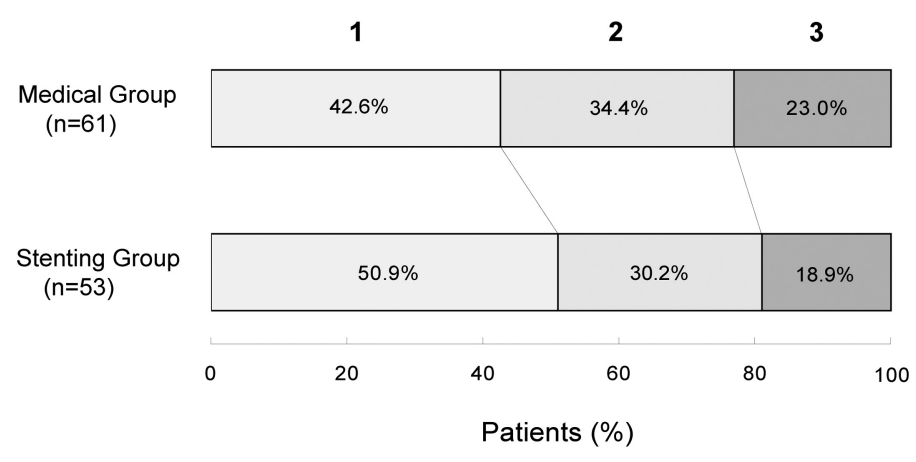

Final $m R S$

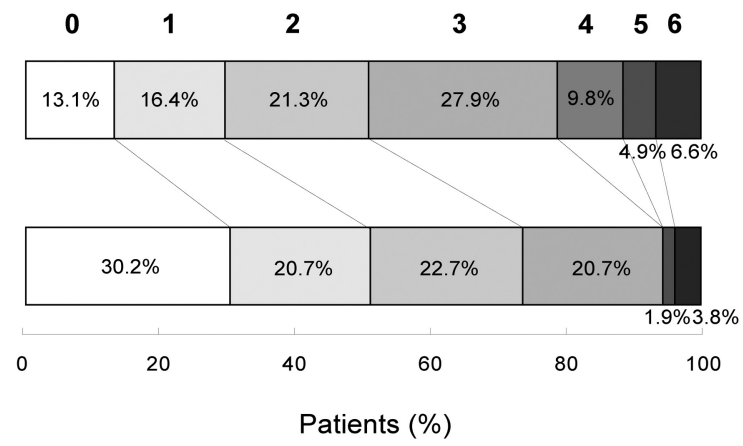

Fig 2. The distribution of baseline and final mRS scores of the medical and stent-placement groups

after stent placement, if possible. The patients in the medical group received single or double antiplatelet and/or anticoagulant treatment following the initial diagnosis. Most patients, although stent-eligible, refused the stent placement treatment $(n=55,90.2 \%)$ because of the procedural risk and/or the expense. A few were stent amenable $(n=6$, $9.8 \%$ ) but had not been offered stent placement due to technical difficulties ( 3 with deep stenotic segments, 2 with tortuous carotid siphons, 1 with a concomitant aneurysm). Both groups were similarly managed and followed at our outpatient clinic on a monthly basis.

\section{Data Collection}

The demographic characteristics, vascular risk factors, comorbidities (hypertension, diabetes, hyperlipidemia, cigarette smoking, stroke/ TIA, ischemic heart disease, peripheral arterial occlusive disease), presenting symptoms, initial diagnosis, clinical events, laboratory surveys, stent placement procedure, and clinical outcomes were reviewed by 2 neurologists through medical records, telephone calls, and outpatient visits. Clinical events were defined as stroke (ischemic or hemorrhagic), TIA, and vascular death other than stroke (including sudden death, death within 30 days after a myocardial infarction, pulmonary embolism, rupture of an aortic aneurysm, or acute ischemia of a limb or internal organ). Major events included disabling stroke and vascular death (mRS score, 4-6). Favorable functional outcome was defined as an mRS score of $0-3$ in the absence of major events during the observation period. Identification of stroke or TIA was based on neurologic deficits and brain MR imaging, including DWI and ADC maps. The MR imaging and DSA of extra- and intracranial vessels were interpreted blindly by 2 neuroradiologists. The stenotic location and degree were estimated according to the method suggested by WASID. ${ }^{3,15}$ The available data regarding blood pressure, $\mathrm{HbA1c}$, and total cholesterol throughout follow-up were evaluated.

\section{Statistics}

The statistical analyses of demographic characteristics between the stent-placement and the medical groups were conducted by using the $\chi^{2}$ test and/or the Fisher exact test and the Mann-Whitney $U$ test and/or the Student $t$ test. The Kaplan-Meier curve and the logrank test were used, respectively, to compare the cumulative event rates and functional outcomes of the 2 groups. Observation time was from the initial diagnosis to primary event occurrence, loss to follow-up, or the patient being event-free until 36 months. The multivariate regression analysis of possible factors related to periprocedural complications was conducted by using stepwise logistic regression including variables with $P \leq .15$ on the univariate analysis. Statistical significance was defined as $P<.05$ in all tests. The analyses were performed by using the Statistical Package for the Social Sciences software, Version 17.0 (SPSS, Chicago, Illinois).

\section{Results}

Of the 114 patients enrolled, comprising 53 patients in the stent-placement group and 61 matched patients in the medical group, there were no significant differences between the 2 groups in terms of basic characteristics, including age, sex, vascular risk factors, presenting symptoms, follow-up time, baseline functional status, stenotic location, and degree of stenosis (Table 1). For all patients, the mean age was $66.5 \pm 12$ years old, and male sex was predominant $(83 \%)$. The most common vascular risk factors were hypertension $(\sim 80 \%)$, followed by diabetes mellitus $(\sim 46 \%)$ and hyperlipidemia $(\sim 34 \%)$. The presenting symptoms, including ischemic stroke and TIA, showed a similar incidence in the 2 groups (37\% and 63\%, respectively). Stenosis was slightly more common in the anterior circulation (59\%) than in the posterior circulation (41\%). The average degree of baseline stenosis was approximately $80 \%$ in both groups. Concomitant extracranial stenosis, rather than isolated intracranial stenosis, was more prevalent in the medical group than in the stent-placement group (54\% versus $36 \%$ ) but not significantly so $(P=.09)$. The mean follow-up time was 17 months in both groups.

The total event rate was similar between the medical group $(24.6 \%)$ and the stent-placement group (26.6\%) during the observation period of 3 years, and the 1-year estimated event rates were $23 \%$ and $22 \%$, respectively (On-line Table and Fig $1 A)$. The major event rate was higher in the medical group $(9.8 \%)$ than in the stent-placement group $(3.2 \%, P=.31)$. Most important, the stent-placement group had a significantly more favorable functional outcome than the medical group (94.3\% versus $78.7 \%$ with $\mathrm{mRS}$ scores of $0-3, P=.045)$. Both groups began with similar distributions of baseline mRS (1-3) but ended with a marked difference in functional outcomes. In particular, the stent-placement group had an increased proportion of asymptomatic patients (30.2\% with $\mathrm{mRS}$ of 0$)$ and a decreased proportion of patients with disability (5.7\% with mRS scores of 4-6) compared with the medical group (Fig 2). Furthermore, the timing of clinical events was different between the 2 groups. The stent-placement group had 75\% (9/ 12) of events clustered in the first week after the procedure as periprocedural events (incidence, 17.0\%). Thereafter, there were only 1 ischemic stroke and 1 TIA during the 3-year follow-up. 


\begin{tabular}{|c|c|c|c|c|c|c|c|c|c|}
\hline \multicolumn{2}{|l|}{ Patient List } & \multirow[b]{2}{*}{ Vessel } & \multirow{2}{*}{$\begin{array}{l}\text { Presentation } \\
(\text { Onset Day) })^{\text {a }}\end{array}$} & \multirow{2}{*}{$\begin{array}{l}\text { Stent } \\
\text { Type }\end{array}$} & \multirow[b]{2}{*}{ Event Pattern } & \multirow[b]{2}{*}{ Pre $^{\mathrm{b}}(\%)$} & \multirow[b]{2}{*}{ Post ${ }^{\mathrm{c}}(\%)$} & \multirow{2}{*}{$\begin{array}{l}\text { Initial } \\
\text { mRS }\end{array}$} & \multirow{2}{*}{$\begin{array}{c}\text { Event } \\
\text { mRS }\end{array}$} \\
\hline No. & Sex/Age (Yr) & & & & & & & & \\
\hline \multicolumn{10}{|c|}{ Ischemic stroke } \\
\hline 1 & $56 / \mathrm{M}$ & CS & Dizziness (2) & B & Embolic infarction & 85 & 10 & 1 & 2 \\
\hline 2 & $75 / M$ & MCA & Stroke (1) & B & Wedge-shaped infarction & 70 & 25 & 3 & 3 \\
\hline 3 & $63 / \mathrm{M}$ & MCA & TIA (1) & B & Perforator infarction & 75 & 20 & 1 & 3 \\
\hline 4 & $54 / \mathrm{M}$ & VBJ & Stroke (3) & B & Perforator infarction & 75 & 10 & 2 & 2 \\
\hline 5 & $65 / M$ & BA & Stroke (2) & B & Perforator infarction & 90 & 10 & 2 & 2 \\
\hline 6 & $85 / F$ & $\mathrm{BA}$ & Stroke (1) & B & Perforator infarction & 90 & 10 & 3 & 3 \\
\hline \multicolumn{10}{|c|}{ Hemorrhagic stroke } \\
\hline 7 & 78/F & CS & Stroke (1) & B & $\mathrm{ICH}, \mathrm{SAH}$ & 75 & 10 & 3 & 5 \\
\hline 8 & $35 / M$ & CS & TIA (1) & B & SAH & 80 & 15 & 2 & 2 \\
\hline 9 & $66 / F$ & MCA & Stroke (1) & B & ICH, SAH & 90 & 40 & 3 & 3 \\
\hline
\end{tabular}

a Symptom onset day 1 indicates the same day poststenting.

brestenting.

c poststenting.

In contrast, the medical group had progressively increasing events with time after the initial diagnosis (Fig $1 A$ ) and a significant cumulative disabling outcome (Fig $1 B$ ), as illustrated by the Kaplan-Meier curves. Long-term events in the medical group included 11 ischemic strokes and 1 TIA: More than half were ipsilateral to the severely stenotic artery, suggesting poor collaterals despite medical treatment. In-stent restenosis was infrequently observed in the stent-placement group and included 1 patient with TIA at 5 months after stent placement with a balloon-mounted stent over the carotid siphon and another who was asymptomatic at 15.8 months with a selfexpandable stent over the vertebral artery. The 1-year probability of in-stent restenosis was $4 \%$. The medical group rarely had follow-up DSA, making stenotic progression difficult to estimate. Vascular risk factors, such as blood pressure, HbAlc, and total cholesterol, were similarly controlled between the 2 groups throughout the observation period, though patients in the stent-placement group tended to have a lower systolic blood pressure than those in the medical group (129.3 \pm 14.7 versus $142.5 \pm 24.4 \mathrm{~mm} \mathrm{Hg}$ ).

The technical success rate in the stent-placement group, defined as residual stenosis $<50 \%$, was $98.1 \%$ in a total of 71 stents at 56 stenotic arteries in 53 patients; there was 1 marginal $(60 \%)$ residual stenosis. All periprocedural complications were observed within 3 days following intervention and were usually minor strokes (mRS, $1-3$ ), except for 1 serious intracranial and subarachnoid hemorrhage from the carotid siphon (mRS 5, Table 2). Most stents were balloon-mounted $(91.5 \%)$, and only 6 were self-expandable, because the latter type was undergoing an early trial for intracranial applications according to the Department of Health of Taiwan. The most common stenotic sites subjected to endovascular intervention were the intracranial carotid and vertebral arteries, whereas the most frequently complicated sites were the MCA and the BA, with total event rates of $42.9 \%$ for both (Fig 3). Perforator infarction with balloon-mounted stents placed at the perforator-rich MCA and BA was usually observed. The stent-placement sites were independent factors in predicting periprocedural ischemic stroke, whereas no other factors, including age, sex, stenotic degree, anterior or posterior circulation, and vascular risk factors, were significantly correlated with periprocedural complications on multivariate regression analysis.

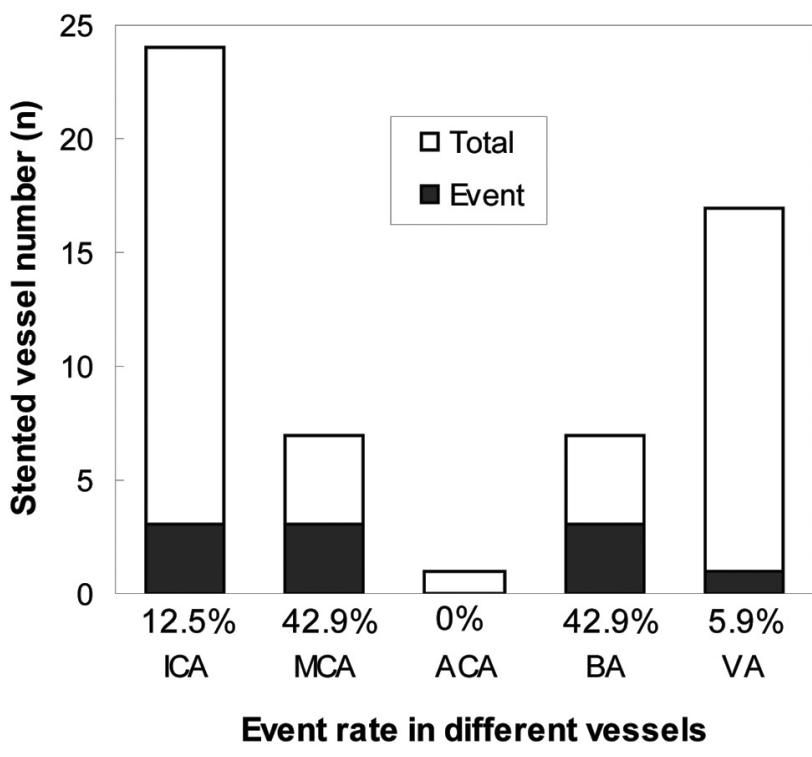

Fig 3. Total clinical events of different stenotic arteries subjected to stent placement. The ICA and VA were the 2 most common interventional sites. Note that the perforator-rich MCA and BA have the most clinical events.

\section{Discussion}

Whether endovascular stent placement is superior to medical treatment for intracranial stenosis has been fiercely debated. ${ }^{16-19}$ In this historical cohort study, 3-year outcomes were compared between endovascular stent placement and medical treatments in 114 Taiwanese patients with angiographically documented severe intracranial stenosis; there was no difference in total event rates between the 2 groups. Although the groups were similar in total event rates, the major event rate was lower in the stent-placement group $(1,3.2 \%)$ than in the medical group $(5,9.8 \%, P=.31)$. The events in the stentplacement group were mostly minor strokes in the first periprocedural week but markedly decreased thereafter compared with the medical group. Most major events in the medical group were large cerebral infarctions within the territory of the stenotic artery. Notably, the stent-placement group had a significantly favorable long-term outcome, and the benefit might arise from augmented reperfusion and collaterals, improved cerebrovascular autoregulation, motivated compli- 
ance for risk-factor control, low in-stent restenosis, and fewer major events.

The present results are compatible with a recent historical cohort study that showed a similar combined ischemic event rate and functional outcome between medical- and stenttreated patients with intracranial stenosis, though stenotic degree $>50 \%$ was not further classified. ${ }^{13}$ There was another report in abstract form from the NIH Wingspan Multicenter Stent Placement Registry suggesting a possible benefit of stent placement in cases of 70\%-99\% intracranial stenosis during a 6-month observation period in comparison with matched medical controls from the WASID trial. ${ }^{12,20}$ In the present study, a long-term functional benefit of stent placement was seen in 70\%-99\% symptomatic intracranial stenoses in terms of no major stroke and $\mathrm{mRS}$ scores between 0 and 3 . However, the medical group had considerably more concomitant extracranial stenoses, which might exert influence on outcome measures. Moreover, limited information concerning longterm risk-factor management and angiographic stenotic progression also restricted our interpretations. We await the ongoing Stent Placement and Aggressive Medical Management for Preventing Stroke in Intracranial Stenosis trial for 70\%99\% stenosis (http://clinicaltrials.gov) to validate the longterm outcomes of the 2 therapeutic modalities.

To reduce subsequent stroke associated with intracranial stenosis, the timely treatment of risk factors is warranted. ${ }^{4,21-23}$ Antithromboembolic agents act in concert with aggressive management of risk factors for plaque stabilization and regression. ${ }^{21}$ In our medical group, the incidence of ischemic events in the first year was $85 \%$ (11 of 13), similar to the rate $(78 \%)$ observed in the WASID study. ${ }^{3}$ This suggests little benefit of delayed stent placement after a year. Furthermore, $69 \%$ (9 of 13) of the ischemic events in the medical group occurred in the territory of the stenotic artery, also similar to the rate of $73 \%$ in the WASID study. ${ }^{24}$ Of these, half (56\%) were in the MCA territory.

The technical success rate of stent placement was $98.1 \%$ in our study; with failure in only 1 patient who had a marginal $60 \%$ residual stenosis at a tortuous carotid siphon. The periprocedural complication rate within the first week was high $(17.0 \%)$, though most were minor strokes (mRS 0-3, $88.9 \%$ ). Previously reported periprocedural complication rates varied from $4.4 \%$ to $50 \%{ }^{7,8}$ Most such studies did not have poststenting brain MR imaging, as in the present study; therefore, the rate of subclinical strokes could have been underestimated. New ischemic foci after carotid stent placement were not uncommon (20\%-50\%) on DWI/ADC imaging, and most were silent ischemic strokes $(\sim 38 \%){ }^{25}$ The most common periprocedural complications in the present study were perforator infarctions ( $4 / 6$ ischemic events) that were related to balloon-mounted stents over the perforator-rich zones of the MCA and BA, similar to an earlier report (5 of 6 ischemic events in a total of 169 patients). ${ }^{26}$

Leung et $\mathrm{al}^{27}$ suggested using self-expandable stents at the perforator-rich MCA and reported no perforator infarction in 24 cases. We used 6 self-expandable stents, and none had periprocedural events, though 1 asymptomatic in-stent restenosis was found a year after stent placement at the VA. In a meta-analysis, self-expandable stents accounted for a higher restenotic rate $(17.4 \%)$ than balloon-mounted stents $(13.8 \%)$ during follow-up for 5-8 months. $^{7}$ The self-expandable Wingspan stent system (Boston Scientific, Natick, Massachusetts) for intracranial stenosis accounted for 25\%-30\% of instent restenosis at 6 months' follow-up. ${ }^{28,29}$ In our study, low in-stent restenosis was observed $(2 / 20,10 \%)$ on angiographic follow-up for at least 6 months, probably because balloonmounted stents were predominantly used (>90\%). Strategically chosen stent types for different sites of intracranial stenosis should optimize therapeutic efficacy.

\section{Conclusions}

The total event rates between the stent-placement and the medical groups were similar for severe intracranial stenosis during a 3-year follow-up. However, the long-term functional outcomes were better in the stent-placement group. The favorable functional outcome resulted partially from the occurrence of fewer major events. The periprocedural complications of stent placement, particularly at the perforator-rich MCA and BA, may be partly prevented by selectively using self-expandable stents.

\section{Acknowledgments}

We thank Wen-Yung Sheng for assistance with statistics.

\section{References}

1. Suri MF, Johnston SC. Epidemiology of intracranial stenosis. J Neuroimaging 2009;19(suppl 1):11S-16S

2. Kasner SE. Natural history of symptomatic intracranial arterial stenosis. J Neuroimaging 2009;19(suppl 1):20S-21S

3. Chimowitz MI, Lynn MJ, Howlett-Smith H, et al. Comparison of warfarin and aspirin for symptomatic intracranial arterial stenosis. $N$ Engl $\mathrm{J} \mathrm{Med}$ 2005;352:1305-16

4. Kasner SE, Chimowitz MI, Lynn MJ, et al. Predictors of ischemic stroke in the territory of a symptomatic intracranial arterial stenosis. Circulation 2006;113:555-63

5. Qureshi AI. Endovascular treatment of cerebrovascular diseases and intracranial neoplasms. Lancet 2004;363:804-13

6. Derdeyn CP, Chimowitz MI. Angioplasty and stenting for atherosclerotic intracranial stenosis: rationale for a randomized clinical trial. Neuroimaging Clin N Am 2007;17:355-63, viii-ix

7. Groschel K, Schnaudigel S, Pilgram SM, et al. A systematic review on outcome after stenting for intracranial atherosclerosis. Stroke 2009;40:e340-47

8. Cruz-Flores S, Diamond AL. Angioplasty for intracranial artery stenosis. Cochrane Database Syst Rev 2006;3:CD004133

9. Nahab F, Lynn MJ, Kasner SE, et al. Risk factors associated with major cerebrovascular complications after intracranial stenting. Neurology 2009;72:2014-19

10. Jiang WJ, Xu XT, Du B, et al. Comparison of elective stenting of severe vs moderate intracranial atherosclerotic stenosis. Neurology 2007;68:420-26

11. Kurre W, Berkefeld J, Brassel F, et al. In-hospital complication rates after stent treatment of 388 symptomatic intracranial stenoses: results from the INTRASTENT Multicentric Registry. Stroke 2010;41:494-98

12. Jarvis AL, Lynn MJ, Alexander MJ, et al. Outcome of patients with 50-99\% intracranial stenosis and TIA or stroke on antithrombotic therapy treated medically vs stenting. In: Proceedings of the 60th Annual Meeting of the American Academy of Neurology. Chicago, Illinois; April 12-19, 2008

13. Samaniego EA, Hetzel S, Thirunarayanan S, et al. Outcome of symptomatic intracranial atherosclerotic disease. Stroke 2009;40:2983-87

14. Zaidat OO. Periprocedural management of patients with endovascular treatment of intracranial atherosclerotic disease. J Neuroimaging 2009;19(suppl 1):35S-38S

15. Schumacher HC, Meyers PM, Higashida RT, et al. Reporting standards for angioplasty and stent-assisted angioplasty for intracranial atherosclerosis. Stroke 2009;40:e348-65

16. Qureshi AI, Feldmann E, Gomez CR, et al. Consensus conference on intracranial atherosclerotic disease: rationale, methodology, and results. J Neuroimaging 2009;19(suppl 1):1S-10S

17. Qureshi AI, Feldmann E, Gomez CR, et al. Intracranial atherosclerotic disease: an update. Ann Neurol 2009;66:730-38

18. Higashida RT, Meyers PM, Connors JJ, et al. Intracranial angioplasty and stenting for cerebral atherosclerosis: a position statement of the American 
Society of Interventional and Therapeutic Neuroradiology, Society of Interventional Radiology, and the American Society of Neuroradiology. J Vasc Interv Radiol 2005;16:1281-85

19. Sacco RL, Adams R, Albers G, et al. Guidelines for prevention of stroke in patients with ischemic stroke or transient ischemic attack: a statement for healthcare professionals from the American Heart Association/American Stroke Association Council on Stroke-co-sponsored by the Council on Cardiovascular Radiology and Intervention. The American Academy of Neurology affirms the value of this guideline. Circulation 2006;113:e409-49

20. Rasmussen PA. The evolution and role of endovascular therapy for the treatment of intracranial atherosclerotic disease. J Neuroimaging 2009;19(suppl 1):30S-34S

21. Gomez CR, Qureshi AI. Medical treatment of patients with intracranial atherosclerotic disease. J Neuroimaging 2009;19(suppl 1):25S-29S

22. Mazighi M, Tanasescu R, Ducrocq X, et al. Prospective study of symptomatic atherothrombotic intracranial stenoses: the GESICA study. Neurology 2006;66:1187-91

23. Wong KS, Chen C, Ng PW, et al. Low-molecular-weight heparin compared with aspirin for the treatment of acute ischaemic stroke in Asian patients with large artery occlusive disease: a randomised study. Lancet Neurol 2007;6:407-13

24. Famakin BM, Chimowitz MI, Lynn MJ, et al. Causes and severity of ischemic stroke in patients with symptomatic intracranial arterial stenosis. Stroke 2009;40:1999-2003

25. Bendszus M, Stoll G. Silent cerebral ischaemia: hidden fingerprints of invasive medical procedures. Lancet Neurol 2006;5:364-72

26. Jiang WJ, Srivastava T, Gao F, et al. Perforator stroke after elective stenting of symptomatic intracranial stenosis. Neurology 2006;66:1868-72

27. Leung TW, Yu SC, Lam WW, et al. Would self-expanding stent occlude middle cerebral artery perforators? Stroke 2009;40:1910-12

28. Levy EI, Turk AS, Albuquerque FC, et al. Wingspan in-stent restenosis and thrombosis: incidence, clinical presentation, and management. Neurosurgery 2007;61:644-50, discussion 650-51

29. Zaidat OO, Klucznik R, Alexander MJ, et al. The NIH registry on use of the Wingspan stent for symptomatic 70-99\% intracranial arterial stenosis. $\mathrm{Neu}$ rology 2008;70:1518-24 